\title{
Thinning treatments had minimal effect on soil compaction in mixed-conifer plantations
}

\author{
by Robert A. York, Richard K. Keller and Ariel C. Thomson
}

If biomass utilization results in soil compaction and reduced forest productivity, the potential benefits may be considered to be not worth the long-term impacts. We analyzed soil strength, an indicator of soil compaction, prior to and following commercial thins (sawlog and biomass harvest) and mastication treatments in 24- to 30-year-old mixedconifer plantations in the central Sierra Nevada. Soil strength in mature, untreated second-growth stands was also measured as a reference. Neither the commercial thins nor the mastication treatments resulted in statistically detectable increases in compaction. Most of the existing compaction came from the original regeneration harvest that established the plantations several decades earlier. It will be important to monitor repeat treatments and long-term effects, but this study suggests that managers should not expect large impacts from thinning treatments on soil compaction in forests such as the one studied here as long as best practices are used.

W orldwide, plantations make up $5 \%$ of forestlands but contribute $15 \%$ of the world's wood production (Carnus et al. 2006). They also play an increasingly important role at the global scale in contributing to a wide variety of social and ecosystem services such as jobs and wildlife habitat (Paquette and Messier 2010). In California, plantations are common on both private and public lands. Especially in locations that are highly productive, these plantations have potential to be valuable for timber production.
When managed for timber or fire hazard reduction, management operations in plantations often involve heavy equipment, which has the potential to reduce soil productivity if the soil compaction effects are great enough. Soil compaction is of special concern because of the repeated use of heavy equipment in young stands, where elevated levels of soil compaction may have occurred already from previous harvests and site preparation operations.

Plantations are ideally structured for mechanized operations. They may be established following even-aged regeneration harvests (e.g., clearcuts) on industrial private lands, or following high severity wildfires across all types of ownerships. Although they can be quite diverse if managed for that objective, plantations are typically associated with homogeneity. Compared to mature tree stands with canopy gaps and developed under- and mid-stories, most plantations have trees that are roughly the same size (if not the same species) and tree density is relatively high and uniform throughout. By one account, in California an even-sized structure (i.e., a bell-shaped diameter

Online: http://californiaagriculture.ucanr.edu/

landingpage. $\mathrm{cfm}$ ?article=ca.v069n03p157\&fulltext=yes

doi: $10.3733 /$ ca.v069n03p157
A harvester-processor thins trees north of Lake Tahoe as part of the U.S. Forest Service Yeti Fuels Reduction Project. 
distribution) is present on $23 \%$ of federal forestland and $31 \%$ of private forestland (William Stewart, UC Berkeley, personal communication). Young, even-aged stands in California forests are common, and they may become even more so as wildfire severity and extent increase and create additional large patches of young planted forests (Collins and Stephens 2010).

Plantations are often identified as highpriority areas for fire hazard reduction treatments because of their high potential value for timber and risk of complete loss during wildfires (Pollet and Omi 2002). In dry mixed-conifer forests, young plantations can burn at particularly high intensities during wildfires. Increased fire intensities in plantations have been both observed (Pollet and Omi 2002) and predicted using fire modeling (Stephens and Moghaddas 2005).

A common fire hazard reduction treatment is density management through mechanical thinning. Thinning that removes small or midrange trees while avoiding large increases in surface fuel can help meet objectives for reducing fire hazard, and it can also be used for increasing physiological resilience in the face of climatic change (Chmura et al. 2011). Thinning young stands may be especially effective from a fire hazard perspective, as trees will develop in size more quickly and therefore be more resistant to fire sooner (Agee and Skinner 2005).
When trees are of commercial size, mechanized thinning can be a cost-effective approach for reducing tree density because treatment costs can be covered with the sale of sawlogs (commercial thinning; fig. 1). Yarding whole trees into landings is of value from a fire hazard perspective because relatively little activity fuel (logging slash) is left behind. The tradeoff, however, is that a net movement of large amounts of biomass debris (treetops and limbs) from forested stands into landings is a necessary byproduct of such operations. The current standard practice is to dispose of large debris piles resulting from mechanized thinning via open burning. Where feasible, the biomass may be hauled away for utilization at a biomass energy facility, avoiding the negative air quality impacts of open burning (e.g., Hurteau et al. 2014).

Many of the plantations in the Sierra Nevada on both public and private lands were established 20 to 40 years ago and the trees are just now becoming large enough to accommodate a commercial thinning. Thinning projects are therefore likely to increase significantly over the next decade, and the increase will be even greater if the demand for biomass material increases. Increased restrictions on open burning because of health concerns will also increase thinning since prescribed burning for density management will be less feasible. Given these

\section{Soil compaction in forests}

$C^{h}$ hanges in soil compaction in forests occur from natural processes such as tree fall, root growth and freeze/thaw cycles. Mechanical operations also cause changes in soil compaction: direct impacts from heavy equipment and dragging (skidding) logs to landings increase compaction; mechanical treatments can also be done to break up compacted soil.

Negative effects of compaction occur when root growth is inhibited by severely compacted soil. Whether compaction reduces productivity at a given site depends to a large degree on soil type. Soils with high clay content are more likely to experience negative effects, while loamy or sandy soils may experience neutral or even positive effects on productivity. Further monitoring of long-term effects and repeated operations is needed to assess trends on time scales that are relevant for forests.

Management practices to avoid soil compaction effects include

- using track-laying machines, which apply less force to soils than rubber-tired machines

- avoiding operations during conditions of high soil moisture, or, as an alternative, conducting operations when the ground is frozen

- re-using skid trails and landings when conducting repeated thinning operations

- utilizing wing-tipped subsoiling to decrease severely compacted soils, especially where clay content is high

developing motives for conducting thinning treatments, there is an especially high demand for understanding the ecological trade-offs between the various thinning treatment methods that can be used.

Most studies of biomass removal impacts involve using treatments that either remove entire mature stands or, to a lesser extent, thin mature stands (PageDumroese et al. 2010). These studies have limited applicability for commercially thinning plantations. Treatment effects in a plantation could be quite different than in a mature stand, especially with respect to soil impacts. A mature secondgrowth stand in the Sierra Nevada has not had a regeneration harvest since railroad logging, often over a century ago (Beesley 1996). Within 10 to 30 years of the establishment of a plantation, however, heavy equipment is often used to conduct thinning and harvest treatments, potentially compounding soil impacts from the relatively recent harvest of the previous stand.

Nutrient depletion of soils following biomass removal is not considered to have long-term impacts unless the site already has relatively low productivity (Page-Dumroese et al. 2010). Operations that result in enough physical compaction to curtail root growth and reduce productivity, however, may be of long-term significance (Grigal 2000; Powers et al. 2005). To minimize compaction effects, thinned trees can be chipped in place with a masticating machine (mastication treatment; fig. 1). A mastication treatment is noncommercial, but it may be predicted to have less of an effect on soil strength than commercial thinning, because only one machine is used (commercial thins have two) and no weight-bearing logs are skidded to landings.

Both treatment types - commercial thinning and mastication - can achieve stand density management objectives but may have very different effects on soil strength. Alternatively, both treatments may have relatively little effect on soil strength if standard practices for avoiding negative impacts are used. Two of the more important practices are operating during dry soil conditions and minimizing skid trails.

In this study, we compared commercial thinning treatments (whole-tree yarding into landings for sawlog and biomass 
harvest) with mastication treatments to measure the effects on soil compaction at the stand level.

We measured soil strength prior to and following treatments using a relatively intensive sampling scheme to increase measurement precision. For reference, we also measured soil strength in mature second-growth forests that had been undisturbed for $\sim 100$ years. In the context of root growth, soil strength is a relevant measure of compaction, because it shows the resistance that a given soil has to root penetration.

\section{Experimental treatments}

Our study took place at Blodgett Forest Research Station (Blodgett Forest) in El Dorado County. Mixed-conifer plantations at elevations between 1,220 and 1,370 meters and between 24 and 30 years

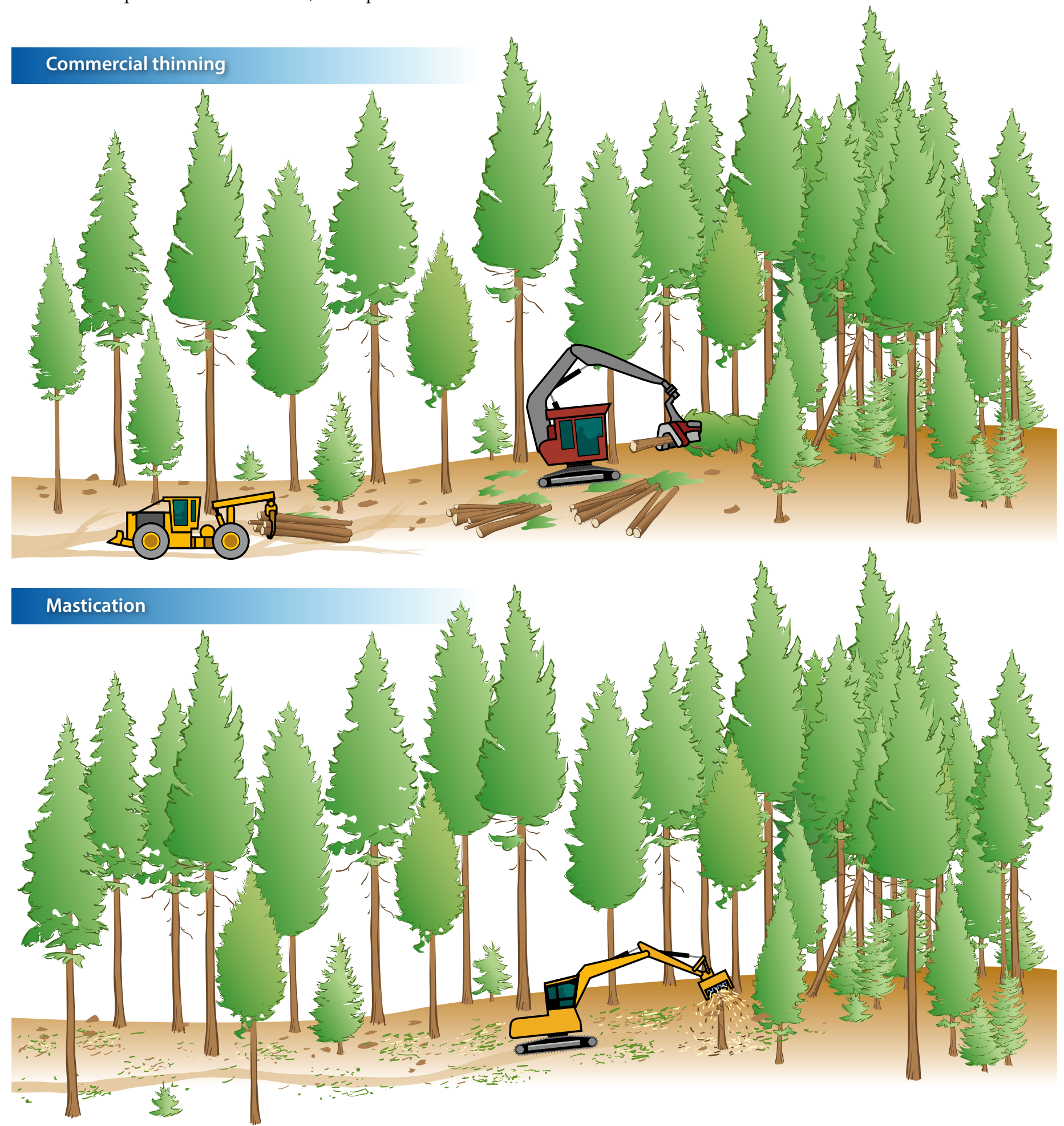

Fig. 1. The study evaluated the soil compaction effects of commercial thinning (top) and mastication (bottom). A commercial thinning operation involves two machines - a feller-buncher to cut and bunch trees; and a skidder to grab the bunches and drag them to a loading area. Mastication involves a single machine that moves through the forest, chopping selected trees and other woody vegetation into small chunks. 
soil moisture (Graecen and Sands 1980) because it influences soil cohesion. Soil moisture was therefore included as a covariate in the analysis of treatment effects on soil strength.

The intent of this study was to detect increases, if any, in soil strength at the stand level as a direct result of treatments and to assess the differences between the mastication and commercial thinning treatments. Plots that fell within skid trails or areas with little disturbance were not thrown out because these locations are part of the stand and their presence is a fundamental outcome of these operations. Skid trails comprise significant proportions of stands following harvesting, ranging from $20 \%$ to $26 \%$ in clear-cuts (Han et al. 2009). Skid trail proportions were not measured in this study, but visual observations suggested they comprised similar levels.

Analysis was done using multivariate ANOVA of repeated measures (MANOVAR). To find potentially different patterns in treatment effects at different depths, the analysis was repeated separately for each depth in 20-millimeter increments from 20 to 500 millimeters. The time series were the before and after measurements of soil strength. Predictor variables included treatment (mastication or commercial thinning) as well as the difference in soil moisture content between the before and after measurements. Including the difference in soil moisture content as a covariate accounted for any differences in soil moisture between the two sampling times.

The time $\times$ treatment interaction was the main effect of interest because it tested for differences in soil strength temporal trends between masticated and thinned stands (i.e., it tested if one type of treatment caused more or less compaction than the other). The within-subject effect of time was also of interest, because it indicated whether there was any overall trend in soil strength (i.e., it tested if, in general, the operations caused compaction). The time $\times$ soil moisture change interaction was an important variable to include in the model to account for any difference in soil moisture before and after treatments.

Statistical conclusions were based on F-test statistics with the determination at $P<0.05$. A final comparison of mean pretreatment soil strength in these stands (all

TABLE 1. Soil strength measurements before and after mastication and commercial thinning treatments at Blodgett Forest, CA

\begin{tabular}{|c|c|c|c|c|c|c|}
\hline Depth* & $\begin{array}{c}\text { Strength } \\
\text { before } \\
\text { mastication }\end{array}$ & $\begin{array}{l}\text { Strength after } \\
\text { mastication }\end{array}$ & $\begin{array}{l}\text { Strength } \\
\text { before } \\
\text { commercial } \\
\text { thin }\end{array}$ & $\begin{array}{l}\text { Strength after } \\
\text { commercial } \\
\text { thin }\end{array}$ & $\begin{array}{c}P \text {-value of } \\
\text { overall trend } \dagger\end{array}$ & $\begin{array}{c}P \text {-value of } \\
\text { treatment } \\
\text { effect } †\end{array}$ \\
\hline$m m$ & \multicolumn{6}{|c|}{ 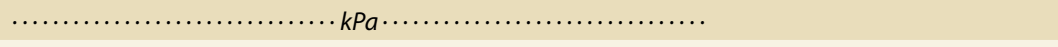 } \\
\hline 80 & 839 & 1,071 & 1,339 & 1,657 & 0.13 & 0.73 \\
\hline 180 & 1,562 & 1,816 & 1,733 & 2,309 & 0.38 & 0.37 \\
\hline 280 & 1,615 & 1,952 & 1,733 & 2,301 & 0.30 & 0.53 \\
\hline 380 & 1,766 & 2,148 & 1,819 & 2,461 & 0.43 & 0.52 \\
\hline 480 & 1,973 & 2,424 & 1,917 & 2,517 & 0.61 & 0.79 \\
\hline
\end{tabular}

* To reduce table size, results are given for depths at 100-millimeter increments.

$+P$-values are from a multivariate analysis of variance with time as the between subject variable.

treatment plus control stands averaged) versus soil strength found in reserve stands where no operations have taken place for $\sim 100$ years was also done. This comparison provided a basic reference for soil strength conditions that occurred following an extended period of no operations. Two reserve stands where no operations have occurred were available for comparison. For a simple comparison of soil strength within these treatment stands versus the reserve stands, standard errors of mean soil strength in treatment stands were calculated for each depth and compared against a baseline, derived from the mean measured in the two reserve stands.

\section{No statistical differences}

Although before and after measurements occurred at the same time of year, soil moisture content measurements taken at the time of soil strength sampling indicated that the soils were slightly drier during the post-treatment measurements than during the pre-treatment measurements. Mean soil moisture at the stand level was $45 \%$ prior to treatments and $33 \%$ following treatments. The decline in soil moisture was related to the seasonal dry-down of the soil, not the treatments themselves. A nearby weather station that recorded soil moisture at hourly increments throughout the study period recorded a similar rate of dry-down between measurement periods (from $28 \%$ to $17 \%$ at the weather station). The decline in soil moisture was identical between the masticated and commercially thinned stands (confirmed with a $t$-test; $P=0.99$ ). This confirmed the importance of including soil moisture as a covariable in the analysis, and also confirmed that the treatment effects on soil strength were not caused by a difference in soil moisture related to the treatments themselves.

Despite the effort to maximize plotlevel precision and careful relocating of before and after measurements, no overall increases in soil strength were detectable with statistical tests at any depth following the treatments, nor were there significant differences between the commercial thinning and mastication treatments. In general, soil strength did increase following treatments, from $1,605 \mathrm{kPa}$ averaged across all depths to 2,091 kPa, but variability was high and $P$-values were far greater than 0.1 (table 1). Coefficients of variation at the stand level averaged $16 \%$ prior to treatments and increased to $29 \%$ following treatments.

The overall increase in soil strength was likely related at least to some degree to soil moisture, which as noted above was slightly drier following the treatments. The time $\times$ soil moisture variable was not significant, but it did consistently have more leverage in explaining soil strength than did the treatments. The results suggest that soil strength increases were not of great enough magnitude to detect operations-caused trends or differences between commercial thinning and mastication, given soil strength variability, which increased following treatments.

Prior to treatment, the soil strength pattern along the depth profile when all seven stands were grouped together followed what is typically observed: soil strength increases rapidly in shallow depths and increases at a much slower rate at greater depths (fig. 2). Despite the lack of a detectable increase in soil strength from either type of operation, it is clear that soil strength is, as expected, 
higher in actively managed stands than in reserve stands. This was especially the case at depths between 100 and 300 millimeters, but it was also true at the greatest depth (500 millimeters) measured for this study.

\section{Soil compaction in perspective}

The effects of mechanical operations on the physical properties of forest soils are highly complex, depending upon sitespecific soil conditions such as texture, soil moisture, root density, aeration and many other factors (Ballard 2000; Graecen and Sands 1980). The effects are also complex because the machinery operates sporadically, both in time and space. This is most evident where machine traffic is especially high. It has been documented consistently that compaction occurs in skid trails to a degree high enough to influence productivity (e.g., Froehlich et al. 1986; Moghaddas and Stephens 2008). Machines do not pass on all locations within a stand, however, and compaction effects can be relatively small or nonexistent only meters away from skid trails (Hatchett et al. 2006).

Because of the lack of skid trails in mastication treatments and because only one machine, instead of two, passed over the masticated areas, we expected to find that the mastication treatments had a noticeably lower effect on soil strength. No difference was detected, which could be interpreted as being the result of either a smaller-than-expected effect of commercial thinning or a larger-than-expected effect of mastication. Given the lack of any trend found in soil strength when all of the treatment areas were combined, we interpret the primary reason as being a smaller-than-expected effect by commercial thinning. In other words, the mastication treatment, as expected, did not compact soils significantly, but neither did the commercial thinning treatment.

It is important to note that variability in measured effects was high and contributed at least somewhat to the inability to detect differences. Replicating further at the stand level is difficult because of space and cost limitations. Greater replication, however, would be necessary to increase the experimental power enough to overcome within-stand variability.

In Sierra Nevada soils, texture has a profound influence on compaction effects, to the point where relatively severe compaction may cause negative, neutral or even positive effects on productivity depending on the soil texture (Gomez et al. 2002). The loamy soil textures of the stands in this study are expected to have

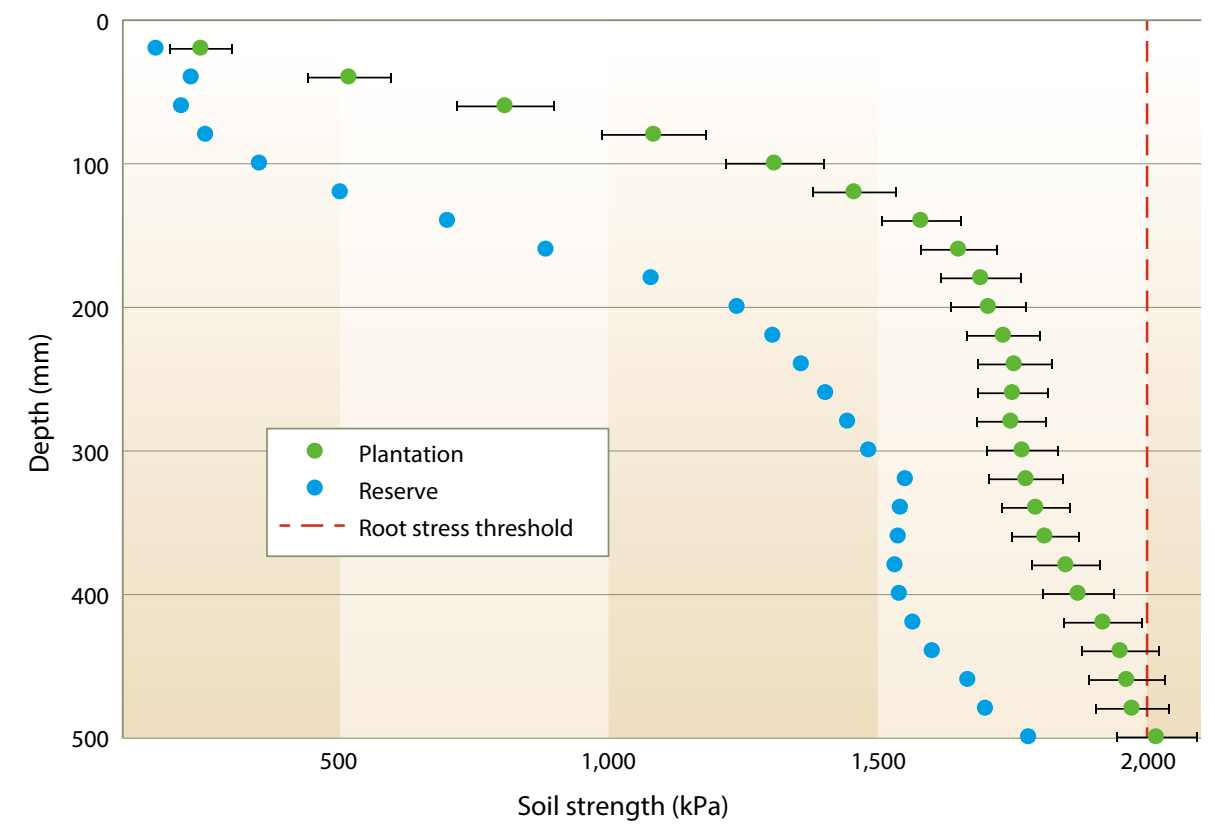

Fig. 2. Soil strength profiles at Blodgett Forest, California. Means are provided with standard error whiskers for seven plantation stands between 24 and 30 years old prior to mastication or commercial thinning treatments. Two reserve stands that were railroad harvested roughly 100 years ago and not manipulated since then were measured for reference. The vertical line represents a conservative estimate of the point when soil compaction might begin to negatively influence root growth.

a moderate capacity to withstand compaction, and compaction may even increase productivity due to increased water retention and hydraulic conductivity (Powers et al. 2005).

While it is well understood that compaction can reduce growth (Froehlich et al. 1986), there is no standard threshold at which negative effects on productivity may be expected, although 3,000 kPa is often cited as a critical point (Graecen and Sands 1980; Zyuz 1968). For our study, we set a soil strength threshold of 2,000 $\mathrm{kPa}$ (the vertical line in figure 2), which is a highly conservative threshold to use for these stands during soil moisture conditions typical of the growing season. Despite the clearly greater soil strength in the pre-treatment plantation stands compared with the undisturbed reserve stands, this conservative threshold was reached in the plantation stands only at the deepest levels of the soil profile.

The difference in pre-treatment soil strength in the treatment stands compared with the soil strength in the undisturbed reserve stands suggests that the majority of physical soil effects occurred in the past - several decades ago, when the sites were logged, with large trees felled and skidded in multiple machine passes, and the site prepared for regeneration. These stands are still under the lagging effect of initial compaction, when $\log$ loads were heavy enough to increase soil compaction relatively deep in the soil profile (Danfors 1974), as suggested in figure 2 .

While this study suggests that no negative effects of soil compaction upon growth may be expected from operations in these soils, it is nonetheless important to continue to monitor the cumulative effects of repeated treatments over time. Whether managed over the long term for timber productivity, low fire hazard or resilience to climatic stress, these plantations and others in the Sierra Nevada will be considered for mechanical treatments as a wide variety of landowners consider diverse objectives. Long-term monitoring within the operational context and scales used in this study will be important.

As more mechanical treatments are repeated over time (a long-rotation plantation may have three or four commercial thins), possible outcomes include a compounding upward trend in compaction over time, no trend at all or a decreasing 
trend as processes that cause physical soil movement (e.g., freeze/thaw cycles) cause a recovery from the initial and subsequent harvests. Monitoring that includes a high plot-level precision and untreated control stands, as in our study, should detect any correlation between soil compaction levels and growth over time.

\section{Management implications}

Implications from this study are most relevant for areas of the Sierra Nevada mixed-conifer forest with similar soil productivity and texture. Blodgett Forest has a midlevel productivity for forests classified in the upper tier of productivity (i.e., site class I). Productive mixed-conifer forests such as these are common between 900 and 1,800 meters on the western slopes of the Sierra Nevada. Results are most directly applicable to forests with a similar loamy soil texture. Care should be taken when extending the results to other textures, especially clayey soils.

Potential effects of soil compaction include changes in forest structure, soil moisture holding capacity, resistance to root growth and increased runoff. For good reason, effects of operations on soil compaction should be considered. While coarser soils appear to be more resilient to the effects of compaction, each compaction event from mechanical treatments may shift the soil, albeit slightly, toward a finer texture by incrementally reducing pore size. If thinnings are done too frequently to allow for recovery between them, the soil may become vulnerable to compaction, especially in terms of reduced water holding capacity on clayey soils (Hill and Sumner 1967). Further studies may help clarify the relationship between soil strength and silvicultural decisions such as commercial thinning frequency and rotation age in plantations.

The degree of compaction observed in this study is still far less than the degree experimentally created by Gomez et al. (2002), who compacted loamy soils close to our study site to $>3,000 \mathrm{kPa}$ below 10 centimeters depth and still found no significant effect of compaction on above-ground tree productivity. Meeting objectives of fire hazard reduction, timber productivity or forest health using mechanical treatments in plantations such as the ones studied here do not appear to negatively affect productivity related to increased soil strength, although repeated

\section{Meeting objectives of fire hazard reduction, timber productivity or forest health using mechanical treatments in plantations such as the ones studied here do not appear to negatively affect productivity.}

treatments will be worth monitoring. Our study adds to the large body of literature suggesting that short-term objectives of fuel treatments can be met with little negative consequences on major ecosystem processes (Stephens et al. 2012).

This conclusion that negative impacts can be avoided, however, assumes that best practices are used to continue avoiding negative impacts. Best practices include, most importantly, avoiding operations with heavy equipment when soils are saturated with moisture. Additionally, equipment that uses less ground force, such as tracked rather than wheeled machines, are preferred. Over the long term, the input of organic matter into soil may

\section{References}

Agee JK, Skinner CN. 2005. Basic principles of forest fuel reduction treatments. Forest Ecol Manag 211:83-96. Ballard TM. 2000. Impacts of forest management on northern forests. Forest Ecol Manag 133:37-42.

Beesley D. 1996. Reconstructing the landscape: An environmental history, 1820-1960. In: Sierra Nevada Ecosystem Project: Final Report to Congress, Vol. II, Assessments and Scientific Basis for Management Options. Davis: University of California, Centers for Water and Wildland Resources. p 1-24

Carnus J-M, Parrotta J, Brockerhoff E. 2006. Planted forests and biodiversity. J Forest 104:65-77.

Chmura DJ, Anderson PD, Howe GT, et al. 2012. Forest responses to climate change in the northwestern United States: Ecophysiological foundations for adaptive management. Forest Ecol Manag 261:1121-42.

Collins BM, Stephens SL. 2010. Stand-replacing patches within a "mixed severity" fire regime: Quantitative characterization using recent fires in a long-established natural fire area. Landscape Ecol 25:927-39.

Danfors B. 1974. Compaction in the subsoil. Swedish Institute of Agricultural Engineering. Special Publication No. 5.

Froehlich HA, Miles DWR, Robbins RW. 1986. Soil bulk density recovery on compacted skid trails in central Idaho. Soil Sci Soc Am J 49:1015-7.

Gomez A, Powers RF, Singer MJ, Horwath WR. 2002. Soil compaction effects on growth of young ponderosa pine following litter removal in California's Sierra Nevada. Soil Sci Soc Am J 66:1334-43.

Graecen EL, Sands R. 1980. Compaction of forest soils: A review. Aust J Soil Res 18:163-89.

Grigal DF. 2000. Effects of extensive forest management on soil productivity. Forest Ecol Manag 138:167-85.

Han S-K, Han H-S, Page-Dumroese DS, Johnson LR. 2009. Soil compaction associated with cut-to-length and whole-tree harvesting of a coniferous forest. Can J Forest Res 39:976-89. be important as well, and can be ensured by maintaining a vegetative understory layer. Finally, skid trail length should be minimized and skid trails should be reused when possible. CA
R.A. York is Research Stations Manager and Adjunct Assistant Professor of Forestry in the UC Center for Forestry and Department of Environmental Science, Policy and Management at UC Berkeley; R.K. Keller is Assistant Forester at Jefferson Resource Company; and A.C. Thomson is Assistant Forester at the UC Center for Forestry.

California Agriculture thanks Guest Associate Editor Bill Stewart for his work on this article.
Hatchett B, Hogan MP, Grismer ME. 2006. Mechanical mastication thins Lake Tahoe forest with few adverse impacts. Calif Agr 60:77-82.

Hill JNS, Sumner ME. 1967. Effect of bulk density on moisture characteristics of soils. Soil Sci 103:234-8. Hurteau MD, Westerling AL, Wiedinmyer C, Bryant BP. 2014. Projected effects of climate and development on California wildfire emissions through 2100. Environ Sci Technol 48:2298-304.

Moghaddas EEY, Stephens SL. 2008. Mechanized fuel treatment effects on soil compaction in Sierra Nevada mixed-conifer stands. Forest Ecol Manag 255:3098-106. Page-Dumroese DS, Jurgensen M, Terry T. 2010. Maintaining soil productivity during forest or biomass-toenergy thinning harvests in the western United States. West J Appl For 25:5-11.

Paquette A, Messier C. 2010. The role of plantations in managing the world's forests in the Anthropocene. Front Ecol Environ 8:27-34.

Pollet J, Omi PN. 2002. Effect of thinning and prescribed burning on crown fire severity in ponderosa pine forests. Int J Wildland Fire 11:1-10.

Powers RF, Scott AD, Sanchez FG, et al. 2005. The North American long-term soil productivity experiment: Findings from the first decade of research. Forest Ecol Manag 220:31-50.

Stephens SL, Moghaddas JJ. 2005. Silvicultural and reserve impacts on potential fire behavior and forest conservation: Twenty-five years of experience from Sierra Nevada mixed conifer forests. Biol Cons 125:369-79.

Stephens SL, Mclver JD, Boerner REJ, et al. 2012. The effects of forest fuel-reduction treatments in the United States. Bioscience 62:549-60.

Zyuz NS. 1968. Bulk density and hardness of the Hillocky Sands of the Middle Don. Sov Soil Sci 13:1769-76. 